\title{
Cassava-Starch-Based Films Incorporated with Buriti (Mauritia flexuosa L.) Oil: A New Active and Bioactive Material for Food Packaging Applications
}

\author{
Danusa Silva da Costa ${ }^{1}$, Katiuchia Pereira Takeuchi ${ }^{2}{ }^{(D}$, Richard Marins da Silva $^{1}$ (D), \\ Josemar Gonçalves de Oliveira Filho $^{3}{ }^{(\mathbb{D}}$, Mirella Romanelli Vicente Bertolo ${ }^{4} \mathbb{D}$, Celso Martins Belisário ${ }^{1}$, \\ Mariana Buranelo Egea ${ }^{1, *(D)}$ and Geovana Rocha Plácido ${ }^{1, *}$
}

check for updates

Citation: Costa, D.S.d.; Takeuchi, K.P.; Silva, R.M.d.; Oliveira Filho, J.G.d.; Bertolo, M.R.V.; Belisário, C.M.; Egea, M.B.; Plácido, G.R. Cassava-Starch-Based Films Incorporated with Buriti (Mauritia flexuosa L.) Oil: A New Active and Bioactive Material for Food Packaging Applications. Polysaccharides 2022, 3, 121-135. https://doi.org/10.3390/ polysaccharides 3010006

Academic Editor: Rajkumar Patel

Received: 30 November 2021

Accepted: 6 January 2022

Published: 12 January 2022

Publisher's Note: MDPI stays neutral with regard to jurisdictional claims in published maps and institutional affiliations.

Copyright: (c) 2022 by the authors. Licensee MDPI, Basel, Switzerland. This article is an open access article distributed under the terms and conditions of the Creative Commons Attribution (CC BY) license (https:// creativecommons.org/licenses/by/ $4.0 /)$.
1 Goiano Federal Institute of Education, Science and Technology, Campus Rio Verde, Rio Verde 75902-970, Brazil; danusa_silvacosta@hotmail.com (D.S.d.C.); richard_91@hotmail.com.br (R.M.d.S.); celso.belisario@ifgoiano.edu.br (C.M.B.)

2 Department of Food and Nutrition, Faculty of Nutrition, Federal University of Mato Grosso, Cuiabá 78060-900, Brazil; katiuchia.takeuchi@gmail.com

3 School of Pharmaceutical Sciences, São Paulo State University (UNESP), Araraquara 14801-903, Brazil; josemar.gooliver@gmail.com

4 São Carlos Institute of Chemistry (IQSC), University of São Paulo (USP), São Carlos 13566-590, Brazil; mirella.bertolo@usp.br

* Correspondence: mariana.egea@ifgoiano.edu.br (M.B.E.); geovana.placido@ifgoiano.edu.br (G.R.P.)

\begin{abstract}
The objective of this study was to develop and characterize cassava-starch-based films incorporated with buriti (Mauritia flexuosa L.) oil and emulsifier (Tween 20). An experimental factorial design $2^{2}$ with three central points was used to develop the films, by varying the concentrations of buriti oil $(0.15$ to $0.45 \% w / v)$ and emulsifier $(0.02$ to $0.04 \% w / v)$. Film thickness and weight increased with increasing buriti oil concentration. The water vapor permeability of the films ranged from 0.22 to $0.366 \mathrm{~g} \mathrm{~mm} \mathrm{~h}^{-1} \mathrm{~m}^{-2} \mathrm{kPa}^{-1}$. The tensile strength values varied from 4.21 to $6.95 \mathrm{MPa}$, the elasticity modulus varied from 538.53 to $722.78 \mathrm{MPa}$, and elongation to rupture varied from 1.13 to $1.66 \%$. The film color was characterized as yellowish, dark, and intense (higher oil content); and clear and a low-intensity color (lower oil content). The films presented a total carotenoid content ranging from 3.63 to $29.73 \mu \mathrm{g} \beta$-carotene/g, which may have resulted in their antioxidant potential against $\mathrm{DPPH} \bullet$ (1,1-diphenyl-2-picryl-hydrazyl) radical (from 74.28 to $87.74 \%$ ). The central formulation of the experimental design (buriti oil $0.30 \%$ and emulsifier $0.03 \%$ ) presented a good performance and can be applied as packaging for foods with a lower water content and that demand protection against oxidation.
\end{abstract}

Keywords: biopolymer; Mauritia flexuosa L.; food packaging

\section{Introduction}

Traditional packaging plays an important role in the containment and preservation of food. However, these packages are mostly composed of plastic films that are not biodegradable and can cause a negatively impact on the environment [1]. To try to reduce the impact caused by disposable plastic packaging, researchers have directed efforts in scientific research towards the development of materials based on biodegradable natural biopolymers [2]. Biopolymer packaging is made from organic macromolecules, such as polysaccharides, proteins, and lipids, individually or through a combination of these components [3].

Among natural polymers, starch has become one of the most promising replacement candidates for plastic films, due to the combination of an attractive price, availability, and renewability. Starches from different botanical sources such as corn, wheat, cassava, yams, and potatoes, among others, are being investigated for their filmogenic properties [4]. 
However, starch-based films, due to the hydrophilic nature of this polysaccharide, have poor water-barrier properties [5]. The use of lipids (mainly oils or waxes) in these films can improve the resistance to moisture, due to their hydrophobic nature, ameliorating the applicability of biopolymer films as food packaging materials [6].

The development of biodegradable active or bioactive packaging containing natural extracts derived from plants is a strategy of great interest for the food industry [7-9]. Buriti (Mauritia flexuosa L.) is a palm tree found very frequently in Brazil, mainly in the Cerrado and Amazon biomes. The oil extracted from the pulp of the buriti palm, popularly known as buriti oil, contains a high concentration of mono- and polyunsaturated fatty acids, high content of carotenoids (which can confer provitamin A activity), and tocopherols, as well as increased antioxidant and antimicrobial activities [10]. In addition to these characteristics, this oil is rich in oleic acid and other compounds that confer positive effects on health [11].

Due to its diverse properties, buriti oil has the potential to be used as a hydrophobic agent to improve the water-barrier properties of films based on hydrophilic polysaccharides, such as starch, and as an active and bioactive agent, in the development of (i) active films that interact with the food, preserving their quality through the release of antioxidant and antimicrobial compounds, and (ii) bioactive films that carry bioactive compounds that have an important effect on human health [12].

Buriti oil has been used in the development of packaging materials, in combination with the most diverse polymers: Silva et al. [13] incorporated different concentrations of buriti oil in chitosan films and observed improvements in the biodegradability and thermal stability of the films; Silva et al. [14] used buriti oil as an additive in fish gelatin films, applying a multivariate optimization process to determine the best concentrations of each component of the films; Almeida et al. [15] tested four different oils (macadamia, olive, buriti, and pure oleic acid) in zein films, aiming to improve the antioxidant and barrier properties. As far as we know, the combination of buriti oil in cassava-starch films and the use of multivariate optimization tools to choose the most suitable concentrations is unprecedented in the literature; thus, this study aimed to develop cassava-starch-based films incorporated with buriti oil for application as a food packaging material with active and bioactive functions.

\section{Materials and Methods}

The materials used in the formulation of the film-forming solutions in this study were glycerol (lot 80989, Dinâmica, Indaiatuba, Brazil), Tween 20 (Vetec, Duque de Caxias, RJ, Brazil), cassava starch (lot HW294, Amafil, Cianorte, PR, Brazil) (270 g/ kg amylose content, $145 / \mathrm{kg}$ water content, $70.6^{\circ} \mathrm{C}$ gelatinization temperature), and buriti (Mauritia flexuosa L.) oil (Belém, PA, Brazil). All other solvents and reagents used were PA grade and used as such.

\subsection{Experimental Design and Film-Forming Solutions Preparation}

The film-forming solutions were prepared according to a methodology adapted from Acosta et al. [16]. Briefly, the cassava-starch solution ( $3 \% w / v)$ was prepared by stirring (Biomixer 78HW-1, Hexasystems, Tabão da Serra, Brazil), raising gradually the temperature from 20 to $70^{\circ} \mathrm{C}$, and maintaining at $70^{\circ} \mathrm{C}$ for $10 \mathrm{~min}$ to induce starch gelatization. After that, the solution was cooled to $40{ }^{\circ} \mathrm{C}$ and glycerol was added $(0.6 \% \mathrm{w} / \mathrm{v})$. Cassavastarch and glycerol concentrations were chosen based on preliminary solubility studies (unpublished). Separately, the buriti oil and the Tween 20 as an emulsifier (independent variables, factors) were mixed at concentrations according to the experimental design (Table 1 ) at $40{ }^{\circ} \mathrm{C}$, reaching a concentration of $10 \%$ of surfactant in relation to the oil. Finally, the starch-solution was added to this mixture under constant stirring. Seven film-forming solutions were prepared for factorial experimental design $2^{2}$ with 3 central points. 
Table 1. Independent variables (buriti oil and emulsifier concentrations) codified and uncodified used for the preparation of cassava-starch-based films.

\begin{tabular}{ccc}
\hline Film-Forming Solution & Buriti Oil $(\%, w / v)$ & Emulsifier $(\%, w / v)$ \\
\hline A & $-1(0.15)$ & $-1(0.02)$ \\
B & $-1(0.15)$ & $1(0.04)$ \\
C & $1(0.45)$ & $-1(0.02)$ \\
D & $1(0.45)$ & $1(0.04)$ \\
E & $0(0.30)$ & $0(0.03)$ \\
F & $0(0.30)$ & $0(0.03)$ \\
G & $0(0.30)$ & $0(0.03)$ \\
\hline
\end{tabular}

The film-forming dispersions $(25 \mathrm{~mL})$ were cast on Petri dishes (diameter $12 \mathrm{~cm}$ ) and dried at $45^{\circ} \mathrm{C}$ for $24 \mathrm{~h}$. After drying, the films were conditioned in a desiccator containing magnesium nitrate pentahydrate, with a relative humidity $(\mathrm{RH})$ of $53 \%$.

\subsection{Cassava-Starch-Based Film Incorporated with Buriti Oil}

2.2.1. Thickness, Weight, Water Vapor Permeability (WVP), Water Solubility, and Oil Permeability of the Film

The thickness of the films was measured with a digital pachymeter (DIGIMESS-100.212, São Paulo, SP, Brazil) with the sensitivity of $0.4 \mathrm{~mm}$. Ten measurements were carried out, three in the center and six in opposite positions of the films [17].

The film weight was determined using the weight and the area of the films and calculated using Equation (1) [18].

$$
\text { Film weight }\left(\frac{\mathrm{g}}{\mathrm{cm}^{2}}\right)=10,000 \cdot\left(\frac{\mathrm{w}}{\mathrm{a}}\right)
$$

where $\mathrm{w}$ is the film weight $(\mathrm{g})$ and a is the film area $\left(\mathrm{cm}^{2}\right)$.

WVP of the film was measured using film cut into pieces and, later, fixed on polycarbonate permeation cells $\left(8.0 \times 2.7 \mathrm{~cm}^{2}\right)$ containing silica gel and sealing with paraffin, after placing this film into a desiccator, where the relative humidity was maintained at $100 \%$ using distilled water. This apparatus was kept in a BOD (Tecnal TE-371, Piracicaba-SP, Brazil) at $25 \pm 0.5^{\circ} \mathrm{C}$ [19]. The mass of films was followed daily for 7 days, and WVP was calculated using Equation (2).

$$
\mathrm{WVP}\left(\mathrm{g} \mathrm{mm} \mathrm{h}^{-1} \mathrm{~cm}^{-2} \mathrm{~Pa}^{-1}\right)=\left(\frac{\mathrm{W}}{\mathrm{t}}\right) \cdot\left(\frac{\mathrm{x}}{\mathrm{A} \cdot \Delta \mathrm{p}}\right)
$$

where $\mathrm{w}$ is the water loss from the permeation cup, A is the film area, $\mathrm{t}$ is the time of analysis, and $\Delta \mathrm{p}$ is the difference in water vapor pressure between the inside and outside of the cup.

The water solubility of the films was determined according to Gontard et al. [20]. Film samples $(n=3$, diameter $=2 \mathrm{~cm})$ with known weight were immersed in $50 \mathrm{~mL}$ of distilled water and subjected to agitation in an orbital shaker (Warmest, VA, USA) at $60 \mathrm{rpm}$ for $24 \mathrm{~h}$ at $25^{\circ} \mathrm{C}$. The film samples were dried in an oven at $105^{\circ} \mathrm{C}$ for $24 \mathrm{~h}$ to determine the resulting material (not solubilized), and water solubility was calculated using Equation (3).

$$
\text { Water solubility }(\%)=\left(\mathrm{W}_{\mathrm{i}}-\frac{\mathrm{W}_{\mathrm{f}}}{\mathrm{W}_{\mathrm{i}}}\right) \cdot 100
$$

where $W_{i}$ is the initial weight of the film sample before drying and $W_{f}$ is the final weight after drying.

The oil permeability, an indication of the lipid barrier property of the films, was determined according to Tang et al. [21]. Tubes with $5 \mathrm{~mL}$ of soybean oil were sealed with a layer of developed films (diameter $=4 \mathrm{~cm}$ ), followed by filter paper, and conditioned at 
$40 \% \mathrm{RH}$ and $25^{\circ} \mathrm{C}$. The filter paper was weighed daily over 7 days, and the oil permeability coefficient (OPC) was calculated using Equation (4).

$$
\mathrm{OPC}=\left(\frac{\Delta \mathrm{W} \cdot \mathrm{FT}}{\mathrm{A} \cdot \mathrm{t}}\right)
$$

where $\Delta \mathrm{W}$ is the variation of weight with time (g), FT is the average of film thickness (mm), A is film permeation area $\left(\mathrm{mm}^{-2}\right)$, and $\mathrm{t}$ is the time (days). Curves were generated using linear regression to estimate the weight gain over time $(\mathrm{W} / \mathrm{T})$.

\subsubsection{Traction Properties}

Film samples $\left(1.5 \times 10 \mathrm{~cm}^{2}\right)$ of each treatment $(n=15)$ were conditioned for 1 or 5 weeks at $25{ }^{\circ} \mathrm{C}$ and $\mathrm{RH}$ of $53 \%$, and their mechanical behavior was evaluated using an equipment from Instron (Instron, 3367, Grove City, PA, USA) to determinate the tensile strength (TS), the elasticity modulus (EM), and the elongation until shear (ES) of the films, according to the standard method [22]. The samples were fixed in the base and a traction force was realized at a minimum of $50 \mathrm{~mm}$ until rupture.

\subsubsection{Color Evaluation}

Color evaluation $(n=3)$ was performed using a spectrophotometer (Hunterlab ColorFlex EZ, Reston, VA, USA), which provided the $\mathrm{L}^{*}(0=$ black, $100=$ white $), \mathrm{a}^{*}(-60=$ green, $+60=$ red $)$, and $b^{*}(-60=$ blue,$+60=$ yellow $)$ parameters. Based on these data, the parameters chroma and hue were calculated using Equations (5) and (6), respectively.

$$
\begin{aligned}
& C=\sqrt{a^{* 2}+b^{* 2}} \\
& h=\tan ^{-1}\left(\frac{b^{*}}{a^{*}}\right)
\end{aligned}
$$

\subsubsection{Bioactive Compounds and Antioxidant Activity}

The total flavonoid content was determined using a spectrophotometric method, through complexation with aluminum chloride $\left(\mathrm{AlCl}_{3}\right)$, and using pyrocatechin as a standard molecule for quantification [23]. The absorbance was measured using a UV/VIS/NIR spectrophotometer (Perkin Elmer Lambda 750, Waltham, MA, USA) with scanning of 250 to $600 \mathrm{\eta m}$, and the maximum absorbance wavelength was defined as $276 \mathrm{\eta m}$.

The total tannin content was determined using the Folin-Ciocalteu colorimetric method, with tannic acid as the standard molecule for the construction of the calibration curve [24]. The absorbance was measured at a wavelength of $725 \mathrm{\eta m}$.

The total carotenoid content was determined as described by Rodriguez-Amaya et al. [25]. The absorbance was measured using a spectrophotometer, with scanning of 250 to $600 \mathrm{\eta m}$, and the maximum absorbance wavelength was defined as $448 \mathrm{\eta m}$. Total carotenoid content was calculated using Equation (7).

$$
\text { Total carotenoids }\left(\frac{\mu \mathrm{g}}{\mathrm{g}}\right)=\frac{\left(\mathrm{Abs} \cdot \mathrm{F} \cdot 10^{4}\right)}{\left(\mathrm{E}_{1 \mathrm{~cm}}^{1 \%} \cdot \mathrm{w}\right)}
$$

where Abs is the maximum of in $\lambda, F$ is factor of dilution, $\mathrm{E}_{1 \mathrm{~cm}}^{1 \%}$ is the absorptivity coefficient of $\beta$-carotene (2592), and $\mathrm{w}$ is sample weight (g).

Antioxidant activity was evaluated using DPPH• (1,1-diphenyl-2-picryl-hydrazyl) radicals according to Mensor et al. [26]. The absorbance was measured using a spectropho- 
tometer at $518 \mathrm{\eta m}$, and the total antioxidant activity was calculated using Equation (8). Methanol was used as a blank, and the extraction solution was used as a control.

$$
\mathrm{AA}(\%)=100-\left[\frac{\left(\mathrm{Abs}_{\text {sample }}-\mathrm{Abs}_{\text {white }}\right)}{\mathrm{Abs}_{\text {control }}}\right] \cdot 100
$$

\subsubsection{Fourier Transform Infrared Spectroscopy (FTIR)}

The determination of the functional groups present in the films was performed by infrared spectroscopy with a UV/VIS/NIR spectrophotometer (Perkin Elmer Lambda 750 , Waltham, MA, USA) at 4000 to $600 \mathrm{~cm}^{-1}$ with a resolution of $4 \mathrm{~cm}^{-1}$ over 32 scans. For the analysis, the samples were submitted to drying at $45^{\circ} \mathrm{C}$ for $20 \mathrm{~h}$ and grinding for homogeneity.

\subsection{Statistical Analysis}

All analyzes were performed in analytical triplicate. The data were evaluated by analysis of variance (ANOVA), models were generated to evaluate the effect of the concentration of the oil and emulsifier on the parameters under study, and the software used was Statistical version 13.0 trial (Dell $^{\mathrm{TM}}$ Statistica $\left.{ }^{\mathrm{TM}}, 2015\right)$. The FTIR data were processed using OriginPro 8 software.

\section{Results}

\subsection{Physical Properties, Water Solubility, and Oil Permeability of the Films}

Figure $1 \mathrm{a}, \mathrm{b}$ show the effects of incorporation of buriti oil and emulsifier on the thickness and weight of cassava-starch-based films. Only buriti oil significantly affected the thickness and weight of the films (Table 2), which increased with the increase of buriti oil concentrations (Figure 1f,g, respectively). These results are consistent, because film thickness and weight are variables that are related to each other. Furthermore, it is expected that with the increase in the concentration of the agent that is being incorporated into the film, there will be an increase in both variables. Similar behaviors have previously been demonstrated [27].

Figure 1c showed that the emulsifier concentration was the variable with the greatest effect on the WVP of the cassava-starch-based films, with a significant negative interaction between buriti oil and emulsifier. This demonstrates that lower WVP values in cassavastarch-films can be obtained when the concentrations of buriti oil concentration are lower and emulsifier concentration is higher (Figure 1h). WVP is related to the free volume in the polymeric matrix through which water molecules can diffuse and for this reason it is a variable that needs to be minimized in the development of films, as it acts directly on the performance of the barrier function [1]. In the present study, the emulsifier probably acted to promote a more cohesive matrix in the cassava-starch-based film, resulting in a higher difficulty in binding to water molecules. Silva, Hernández, Araújo, Joele, and Lourenço [14] also analyzed the effects of buriti oil and emulsifier on the water barrier property of fish gelatin films; in their case, the lowest WVP values (less than $5.2 \times 10^{-11} \mathrm{~g} \mathrm{~mm}^{-2} \mathrm{~s}^{-1} \mathrm{~Pa}^{-1}$ ) were obtained with lower oil (20-40\%) and emulsifier $(\sim 13 \%)$ concentrations. This result is probably related to the higher buriti oil concentrations tested, when compared to those of this study.

The water solubility of the films was not affected for buriti oil (Figure 1d), while the emulsifier caused a significant negative effect on this variable (Table 2). This indicates that by increasing the emulsifier concentration, lower water solubility is expected for the cassava-starch-based film. This behavior may be related to a greater interaction between the components of the film-forming solution in the presence of an emulsifier, resulting in a less hydrophilic polymeric network [28]. As expected, water solubility and WVP, which are two properties related to the film's ability to interact with water [29], demonstrated a similar behavior in the present work. 


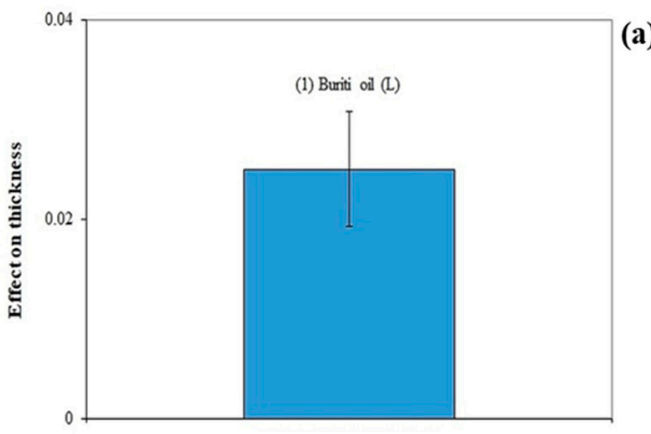

(a)

(b)

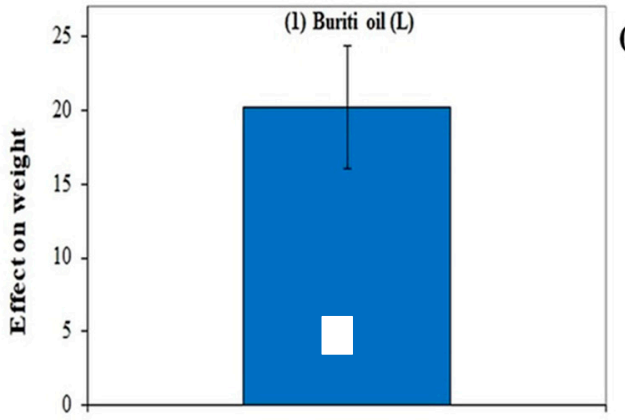

(c)
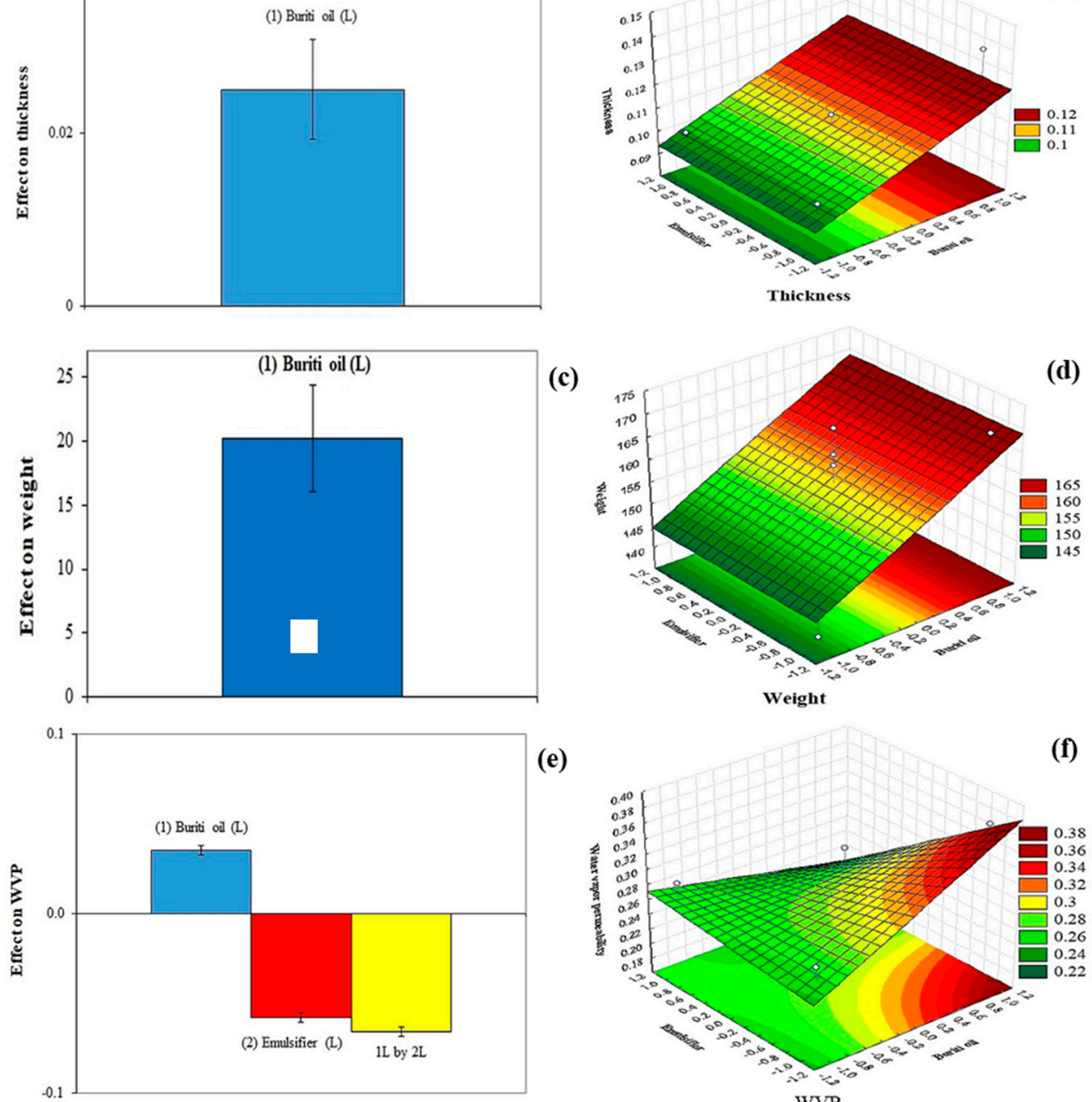

(e)

(f)

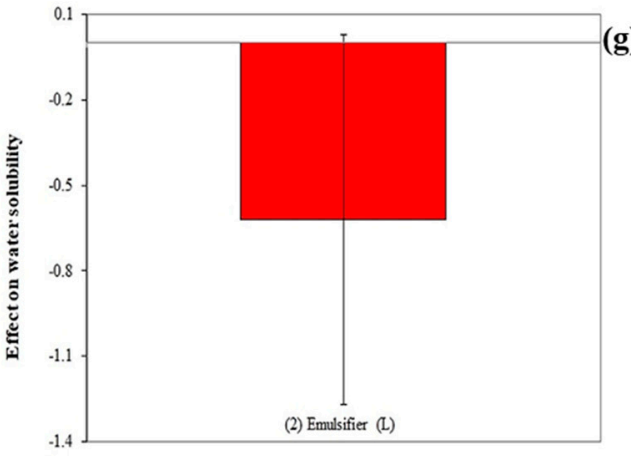

(g)
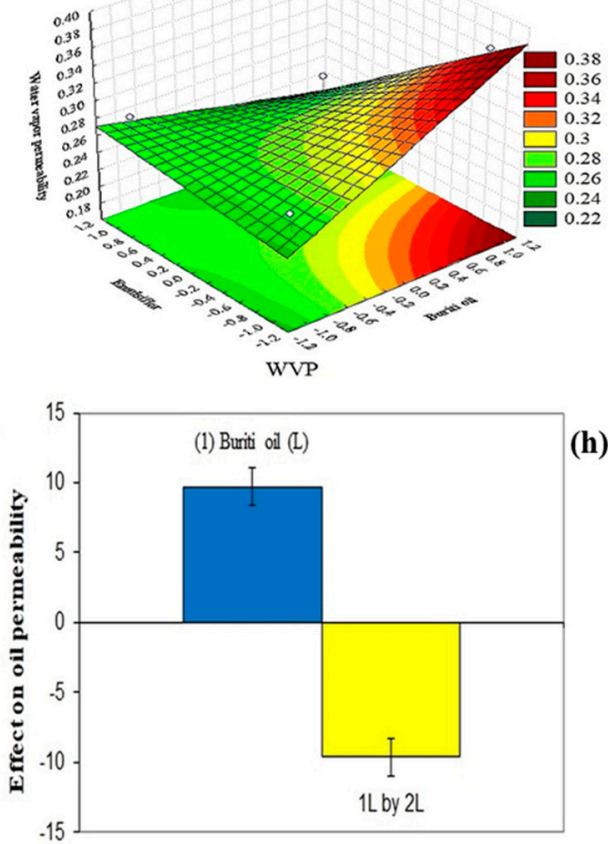

(h)

Figure 1. Effect of buriti oil and emulsifier (Tween 20) on the thickness (a), weight (c), water vapor permeability (WVP) (e), water solubility (g), and oil permeability (h) of the cassava-starch-based films. Response surfaces show the influence of buriti oil and emulsifier on the thickness (b), weight (d), and WVP (f) of films. 
Table 2. Mathematical modeling of the dependent variables (film thickness, film weight, WVP, tensile strength (TS), elasticity modulus (ELM), and elongation (E), color parameters ( ${ }^{*}, h$, and C), bioactive compounds (flavonoids, tannins, carotenoids), and antioxidant activity of the films) according to the results obtained through experiments using the independent variables (buriti oil = $\mathrm{BO}$ and emulsifier $=\mathrm{EM})$.

\begin{tabular}{ccc}
\hline No & Equations & $\mathbf{R}^{\mathbf{2}} \mathbf{( \% )}$ \\
\hline$(9)$ & Film thickness $=0.11+0.013 \mathrm{BO}$ & 83.6 \\
\hline$(10)$ & Film weight $=156.66+10.10 \mathrm{BO}$ & 63.5 \\
\hline$(11)$ & $\mathrm{WVP}=0.28+0.02 \mathrm{BO}-0.029 \mathrm{EM}-0.03 \mathrm{BO} \mathrm{EM}$ & 75.9 \\
\hline$(12)$ & $\mathrm{TS}=5.36-1.20 \mathrm{BO}$ & 79.4 \\
\hline$(13)$ & $\mathrm{ELM}=606.32-60.88 \mathrm{EM}$ & 92.4 \\
\hline$(14)$ & $\mathrm{E}=1.31+0.25 \mathrm{EM}$ & 75.9 \\
\hline$(15)$ & $\mathrm{L}=28.38+1.73 \mathrm{EM}$ & 56.1 \\
\hline$(16)$ & $\mathrm{C}=81.55-0.97 \mathrm{BO}+2.02 \mathrm{EM}+0.75 \mathrm{BO} \mathrm{EM}$ & 98.9 \\
\hline$(17)$ & Flavonoids $=61.62+18.69 \mathrm{BO}+12.08 \mathrm{EM}+9.79 \mathrm{BOxEM}$ & 67.9 \\
\hline$(18)$ & Tanins $=12.76+4.65 \mathrm{BO}$ & 51.3 \\
\hline$(19)$ & Carotenoids $=10.87+8.24 \mathrm{BO}-4.81 \mathrm{EM}-4.45 \mathrm{BOxEM}$ & 90.4 \\
\hline$(20)$ & Antioxidant activity $=81.16+3.04 \mathrm{BO}+2.94 \mathrm{EM}-2.95 \mathrm{BOxEM}$ & 50.2 \\
\hline$(21)$ &
\end{tabular}

The film permeability was positively affected by the buriti oil and negatively affected by the interaction between buriti oil and emulsifier (Figure 1e). This demonstrates that higher concentrations of buriti oil in cassava-starch-based film result in a higher interaction with lipid molecules by the polymer matrix, which increases the oil permeability.

Table 2 shows the mathematical models of the thickness, weight, and WVP of the cassava-starch-based films obtained from the independent variables studied in the present work (buriti oil and emulsifier). In these three cases, the coefficients of determination $\left(R^{2}\right)$ were higher than $60 \%$, while the lack of adjustment was not significant, demonstrating that the modeled equations were well adjusted to the data obtained experimentally. Mathematical models for water solubility and oil permeability are not presented, as they demonstrated a low coefficient of determination $(<20 \%)$.

\subsection{Mechanical Properties of the Films}

Figure 2 shows the effects of buriti oil and emulsifier on the mechanical properties of the cassava-starch-based films. Only buriti oil demonstrated a negative effect, with a significant difference in the tensile strength (Figure 2a) of the films. In this case, the higher concentration of buriti oil resulted in a lower tensile strength of the films. Similar results were reported by Silva, Lopes, da Silva, and Yoshida [13]: increasing buriti oil concentration from 0.1 to $1.5 \%$ led to an almost $5 \mathrm{MPa}$ decrease in the tensile strength of chitosan films. Such an effect could be the result of lower resistance to traction, due to the lower cohesiveness or discontinuity of the polymer matrix [30].

Emulsifier demonstrated a negative effect on the elasticity modulus of the cassavastarch-based films (Figure 2b), showing that a high concentration of emulsifier results in a lower value of elasticity modulus of the films (Figure 2e, Table 2). Emulsifier demonstrated a positive effect on the elongation of the films (Figure 2c), and a high emulsifier concentration resulted in the highest value of elongation of the films (Figure 2f, Table 2). These results corroborate the application of emulsifiers in films, which promotes a better interaction between the mixture components, resulting in more flexible films with better mechanical properties [31]. 

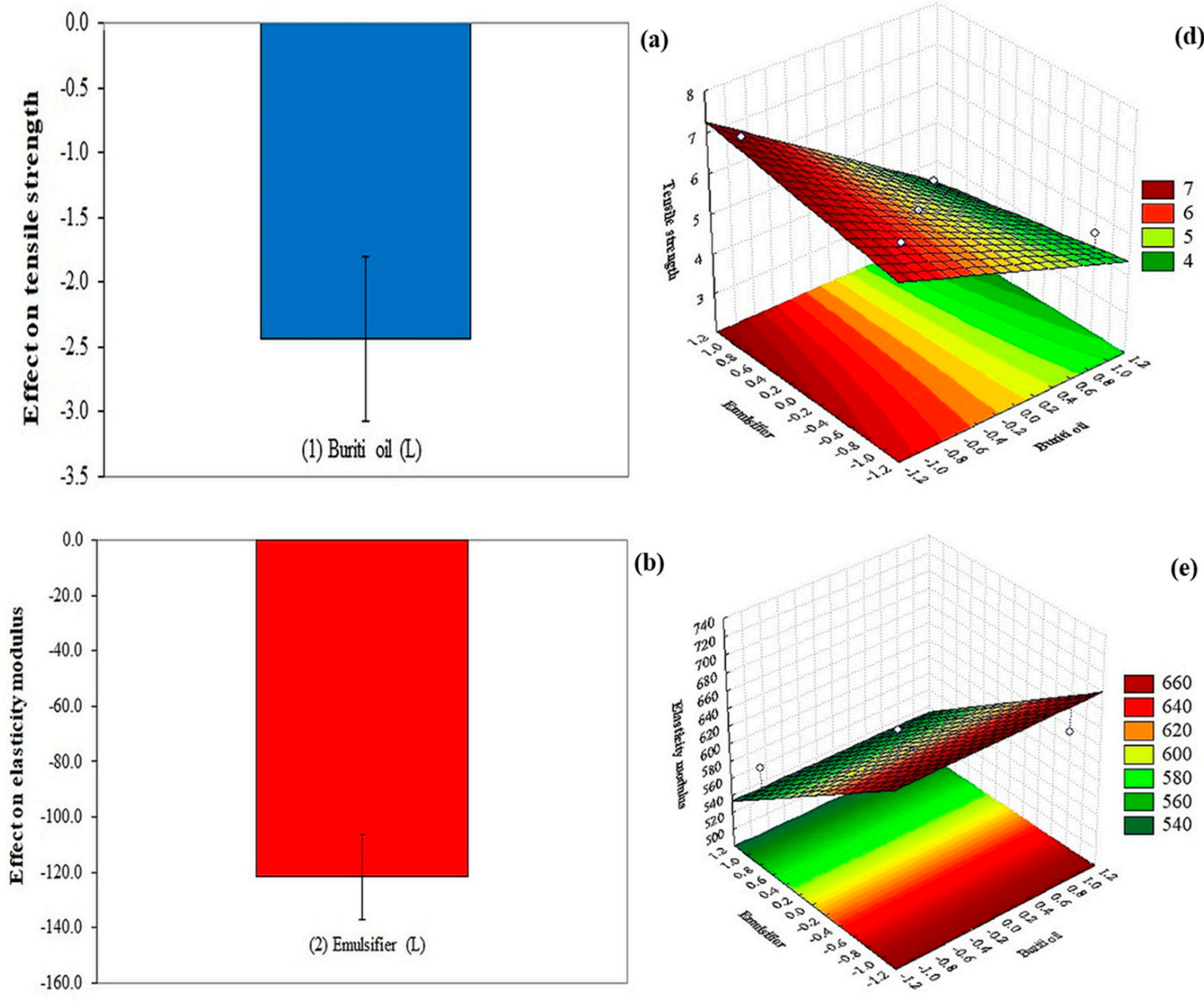

(b)

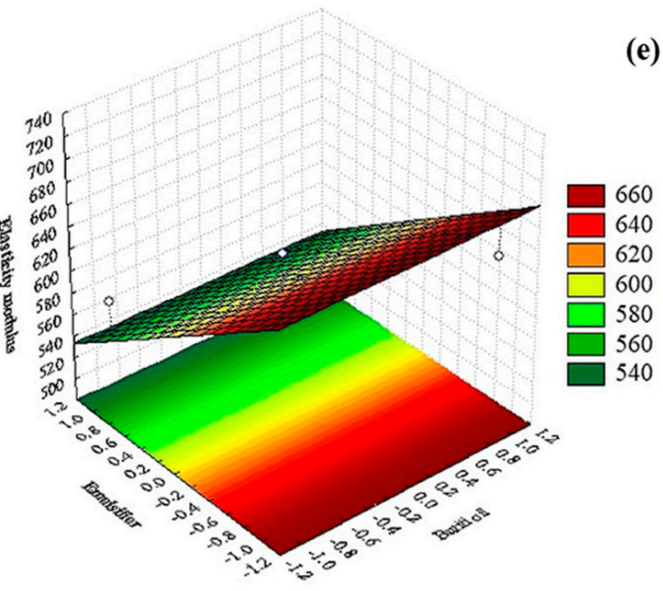

(e)
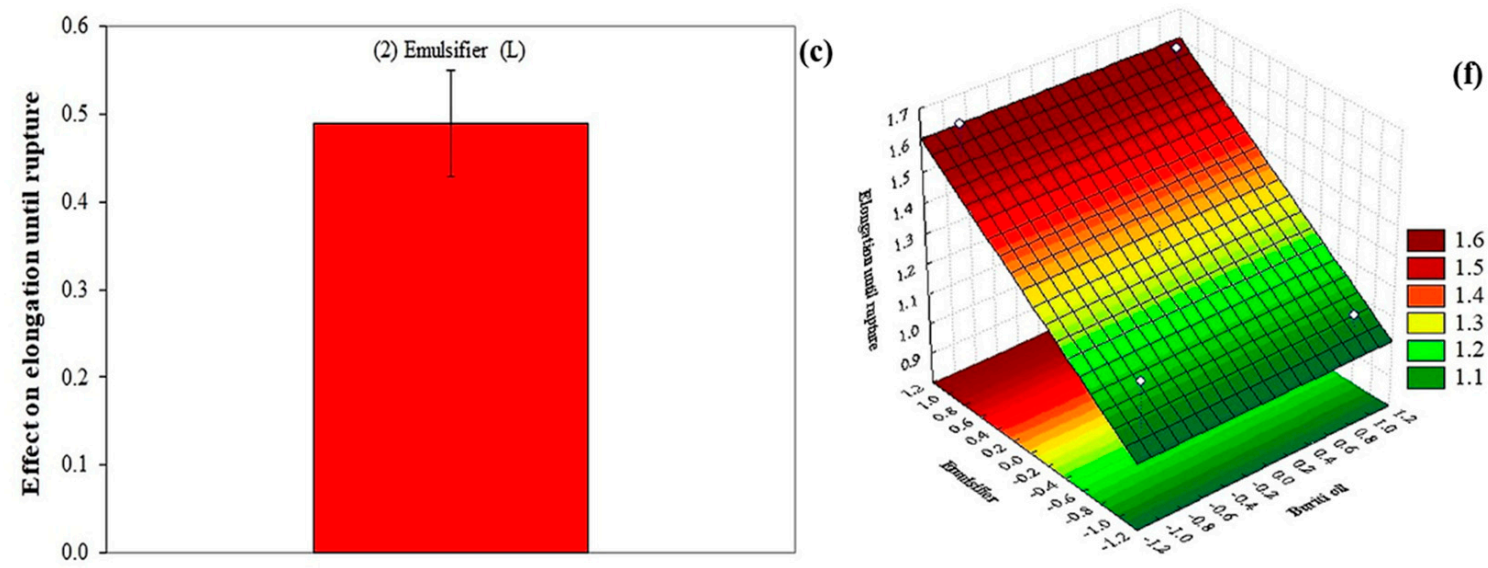

Figure 2. Effect of buriti oil and emulsifier (Tween 20) on the tensile strength (a), elasticity modulus (b), and elongation until rupture (c) of the cassava-starch-based films. Response surfaces show the influence of buriti oil and emulsifier on the tensile strength (d), elasticity modulus (e), and elongation to rupture (f) of the films.

The mathematical modeling of the mechanical properties showed that the coefficients of determination $\left(R^{2}\right)$ were higher than $75 \%$ (Equations (12)-(14); Table 2), while the lack of adjustment was not significant, demonstrating that the modeled equations were well adjusted to the data obtained experimentally. 


\subsection{Color Parameters}

Emulsifier demonstrated a positive effect on the luminosity ( $L^{*}$ parameter) of the films, indicating that the increase in the concentration of this component would result in a film with a higher $\mathrm{L}^{*}$ parameter (Figure $3 \mathrm{a}, \mathrm{d}$; Table 2). In the present work, the values of the $\mathrm{L}^{*}$ parameter ranged from 27 to 30 , which had been reported by Wang et al. [32] as interesting values for films that will be applied to food. Silva, Hernández, Araújo, Joele, and Lourenço [14] reported $\mathrm{L}^{*}$ values more than twice as high for their optimized fish gelatin films containing buriti oil; in their case, the oil significantly influenced the luminosity of the films, decreasing this variable by about 12 units. While the emulsifier positively affected the hue parameter (Figure 3b,e), buriti oil negatively affected the same parameter (Figure 3c,d). This is because buriti oil has a yellow hue that is transferred to the cassava-starch-based film when this ingredient is added. Buriti oil showed a positive effect on the $C$ parameter (Figure 3d), and all developed films presented values below 10. This demonstrated that the increase in the concentration of buriti oil results in an increase in the $C$ parameter (Figure 3e).

The mathematical modeling of the color parameters showed coefficients of determination $\left(R^{2}\right)$ were higher than $50 \%$ (Equations (15)-(17); Table 2), while the lack of adjustment was not significant, demonstrating that the modeled equations were well adjusted to the data obtained in the experimental method (Table 2).

Thus, the colorimetric parameters of the films were influenced by both independent variables. The most desirable results for food films are the use of low emulsifier concentration to produce darker films and high buriti oil concentration for films with higher chromaticity, which is attributed to the lipid droplets distributed through the polymeric matrix, which can scatter the light $[32,33]$.

\subsection{Bioactive Compounds and Antioxidant Activity}

The films developed in the present work showed a total flavonoid content ranging from 0.025 to $0.082 \mathrm{mg}$ pyrocatechin equivalent/100 g. Emulsifier and buriti oil contributed positively to the increase in the concentration of flavonoids in the developed films (Figure 4a,e), and buriti oil showed a higher effect. This demonstrates that by increasing the concentration of both ingredients, a higher total flavonoid content can be expected in the developed film. Flavonoids have a wide range of bioactive properties, such as antioxidant [34], anti-inflammatory [35], anti-diabetic [36], anti-cancer, cardioprotective, and anti-hypertensive [37] activities; and, hence, their inclusion in bioactive films is a strategy that should be considered.

Buriti oil showed a high positive effect on the total tannin content, while the emulsifier had a negative effect (Figure 4b), and the interaction between the two ingredients was not significant. Thus, the highest contributor to the total tannin content was buriti oil (Figure 4f). Similarly to flavonoids, tannins have beneficial properties for human health, such as the ability to reduce blood pressure [38], decrease serum lipid levels [39], produce hepatic necrosis, and modulate immune responses [40].

The films developed in the present work showed total carotenoids content ranging from 3.63 to $29.73 \mu \mathrm{g}$ of $\beta$-carotene/g. Buriti oil positively affected the total carotenoid content, while the emulsifier and the interaction of the two ingredients negatively affected this content (Figure 4c). Thus, for a cassava-starch-based film with a high content of carotenoids, it is necessary to increase the addition of buriti oil (Figure $4 \mathrm{~g}$ ), as buriti oil is the highest contributor to this parameter. This is probably because buriti oil is a good source of carotenoids (values between 600 to $10,000 \mathrm{mg} / \mathrm{kg}$ ) [41], where the main carotenoids found are trans- $\beta$-carotene, $\alpha$-carotene, cis- $\beta$-carotene, mutachrome, cis- $\beta$-carotene, $\zeta$ carotene, phytofluene, $\beta$-zeacarotene, zeaxantine, $\gamma$-carotene, $\beta$-10-apo-carotene, and $\delta$ caroten [42]. The consumption of carotenoids is associated with a lower incidence of cancer, cardiovascular disease (CVD), osteoporosis, diabetes, age-related macular degeneration (AMD), cataract, and infectious diseases, such as HIV infections [43-45]. 

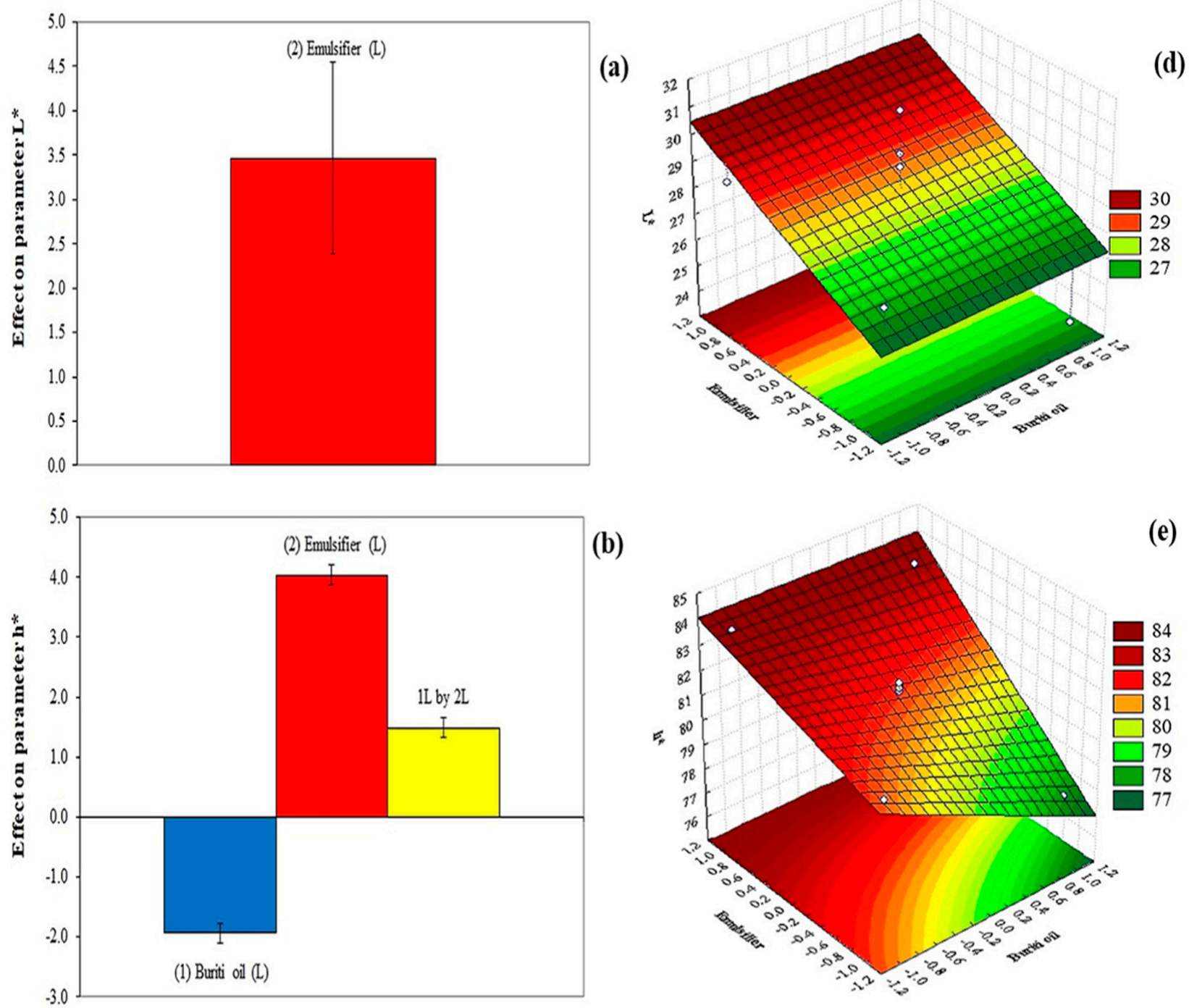

(b)

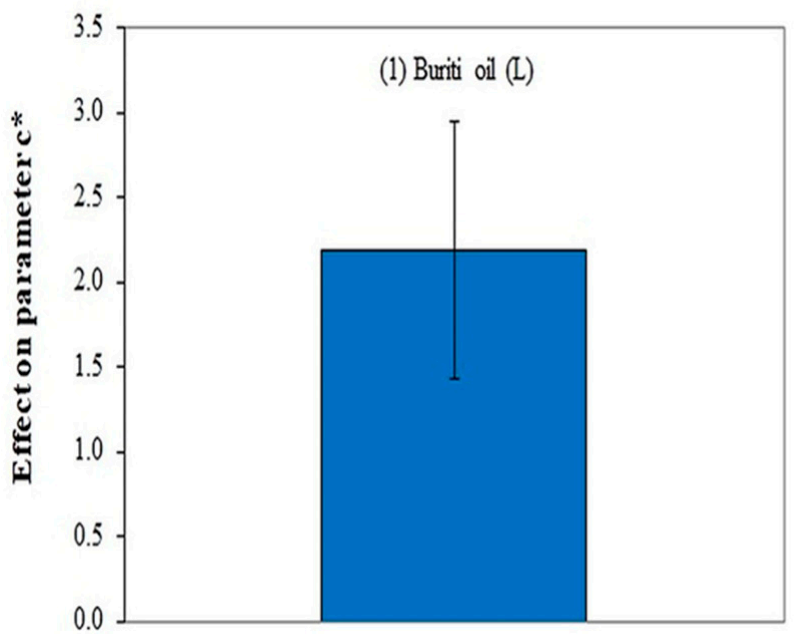

(a)

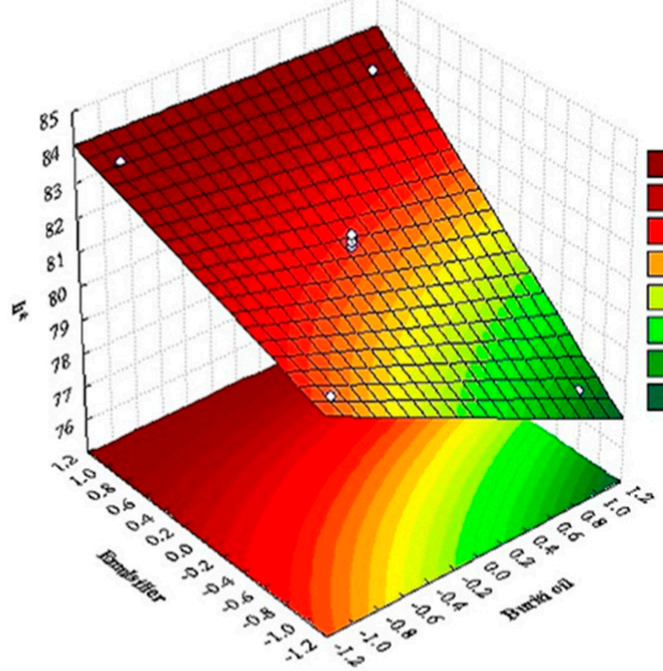

(e)

(d)

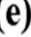

(c)

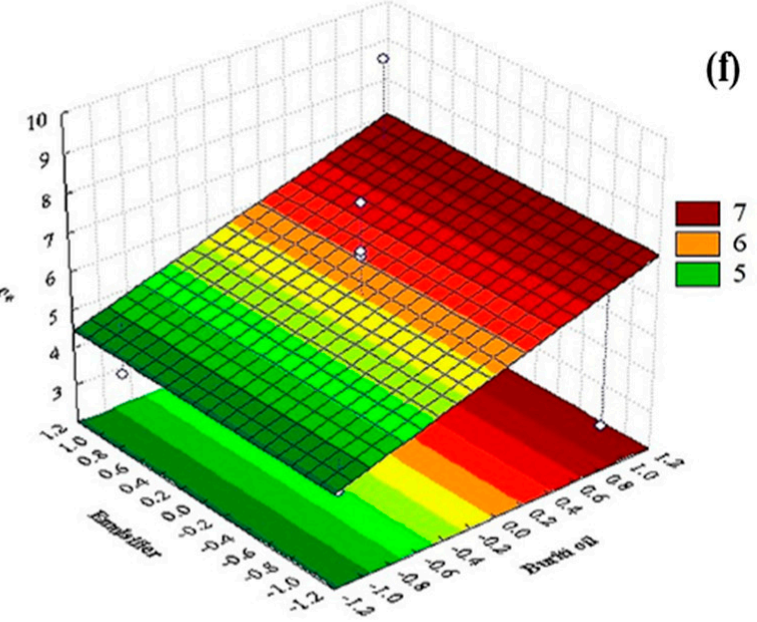

Figure 3. Effect of buriti oil and emulsifier (Tween 20) on the $L^{*}$ parameter (a), hue (b), and chroma (c) parameters of the cassava-starch-based films. Response surfaces showing the influence of buriti oil and emulsifier on the $L^{*}$ parameter $(\mathbf{d})$, hue $\left(\mathrm{h}^{*}\right)(\mathbf{e})$, and chroma $\left(\mathrm{C}^{*}\right)(\mathbf{f})$ parameters of films. 

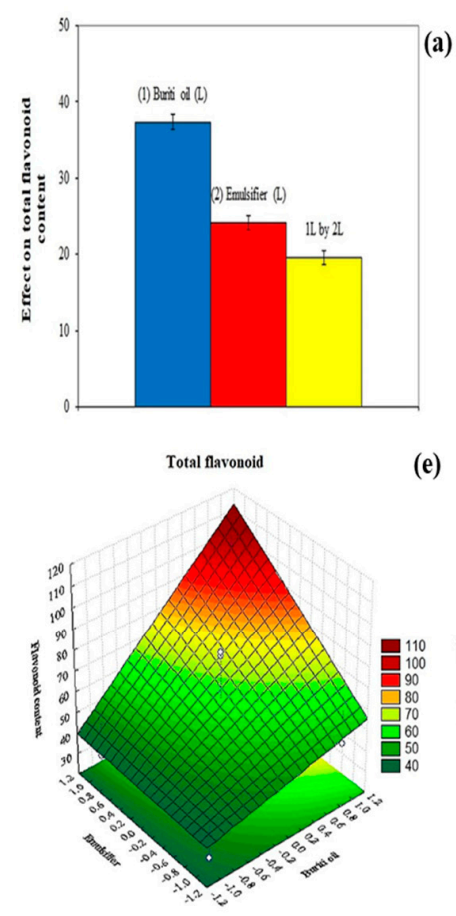

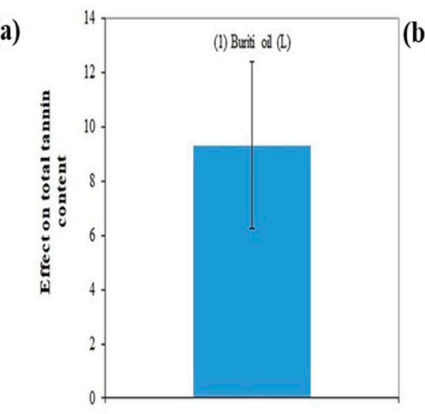

(e)

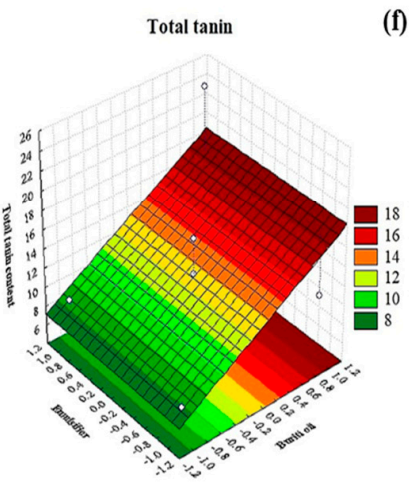

(f) (b)
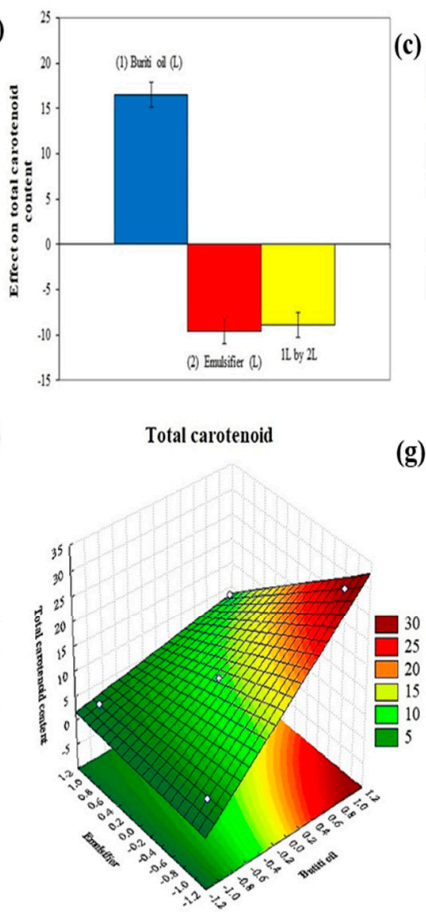

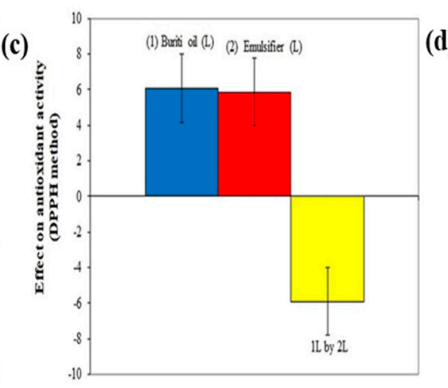

(g)

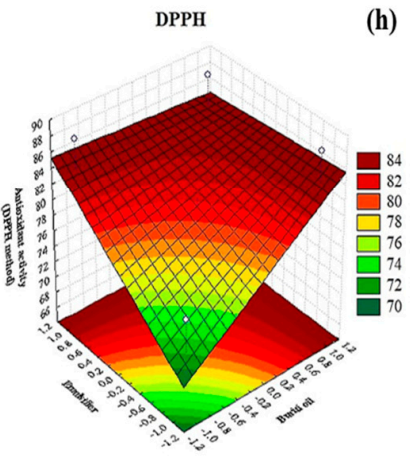

Figure 4. Effect of buriti oil and emulsifier (Tween 20) on total flavonoid content (a), total tannin content (b), total carotenoid content (c), and antioxidant activity (by DPPH method) (d) of the cassavastarch-based films. Response surfaces showing the influence of buriti oil and emulsifier on total flavonoid content (e), total tannin content (f), total carotenoid content (g), and antioxidant activity (by DPPH method) (h) of films.

The use of bioactive compounds such as flavonoids, tannins, and carotenoids in films can provide functional properties to these materials, which could be applied as bioactive edible films. Bioactive films are a new category of edible packaging for food, which can have beneficial effects on the health of consumers, due to the presence of bioactive compounds in their composition [12].

The films presented a free radical capture potential (DPPH•) between 74.28 and $87.74 \%$. Buriti oil and emulsifier positively affected the antioxidant potential of the films, while the interaction between these two ingredients negatively affected this parameter (Figure $4 \mathrm{~d}$ ). This demonstrates that the higher concentration of buriti oil and emulsifier results in a higher free radical scavenging potential of the developed film (Figure 4h). This result is in agreement with previous studies that reported that buriti oil has antioxidant activity with values ranging from 36.53 to $78.07 \%$ of antioxidant activity, using the DPPH method [46].

The mathematical modeling of the mechanical properties showed that the coefficients of determination $\left(R^{2}\right)$ were higher than $50 \%$ (Equations (18)-(21); Table 2), while the lack of adjustment was not significant, demonstrating that the modeled equations were well adjusted to the data obtained experimentally.

Films with antioxidant properties have the potential to be applied as active packaging material for foods, reducing the lipid oxidation of these products and increasing their shelf life. In addition, films with antioxidant properties can also be used for applications such as bioactive edible packaging, which can offer health benefits to consumers [47].

\subsection{Fourier-Transform Infrared Spectroscopy (FTIR)}

Figure 5 shows the Fourier transform infrared spectra for the developed films. All films demonstrated bands in common, related to the main functional groups present in the starch structure, such as the broadband at $3292 \mathrm{~cm}^{-1}$, attributed to the stretching of $\mathrm{O}-\mathrm{H}$ bonds (present both in starch and glycerol structures). At $2923 \mathrm{~cm}^{-1}$, the neighboring band characteristic of the $\mathrm{C}-\mathrm{H}$ axial bonds was also observed in all samples. The band at 
$1743 \mathrm{~cm}^{-1}$, in turn, represents the $\mathrm{C}=\mathrm{O}$ bonds of the fatty acids that belong to the buriti oil. The thin band located from 1150 to $1078 \mathrm{~cm}^{-1}$ can be attributed to the C-O-C and C-O bonds, present in ether and ester groups. Finally, the bands corresponding to the $\mathrm{C}-\mathrm{O}-\mathrm{H}$ and $\mathrm{CH}_{2}$ stretching are located in the region from 1078 to $928 \mathrm{~cm}^{-1}$ [48].

A
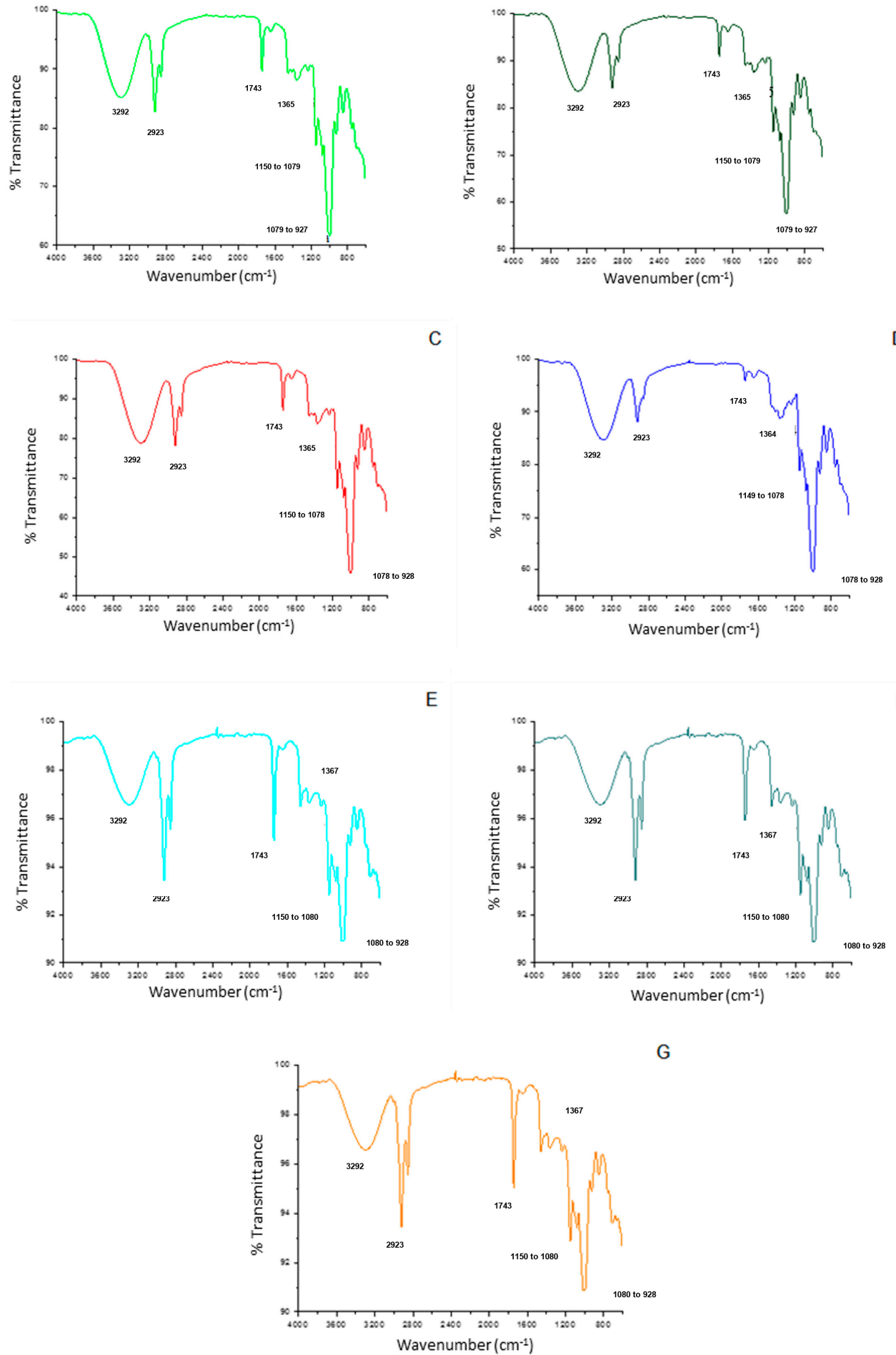

Figure 5. Fourier transform infrared spectra of the cassava starch-based films incorporated with buriti oil. The letters $(\mathbf{A}-\mathbf{G})$ correspond to the seven film-forming solutions prepared according to the coded and real levels from Table 1 . 
The main differences between the spectra can be attributed to the intensity of some bands, such as those referring to O-H, C-H, and C=O bonds (at 3292, 2923, and $1743 \mathrm{~cm}^{-1}$, respectively), all present in characteristic functional groups of both surfactant and buriti oil. The decrease in the intensity of the $\mathrm{C}-\mathrm{H}$ and $\mathrm{C}=\mathrm{O}$ bands in the samples containing higher buriti oil concentrations ( $\mathrm{C}$ and $\mathrm{D})$, when compared to the central point samples (E, $\mathrm{F}$, and $\mathrm{G}$ ), is indicative of the possible interactions occurring between the components of the emulsions, such as hydrogen bonds.

\section{Conclusions}

The development of cassava-starch-based films incorporated with buriti oil was optimized in this study with the use of chemometric tools. The effects of both buriti oil and emulsifier (glycerol) were analyzed in terms of the film barrier, mechanical, and bioactive properties. Buriti oil contributed to increasing the thickness and weight of the films. The best values for water vapor permeability ranged from 0.22 to $0.366 \mathrm{~g} \mathrm{~mm} \mathrm{~h}^{-1} \mathrm{~m}^{-2} \mathrm{kPa}^{-1}$. The optimized values of tensile strength, modulus of elasticity, and elongation to rupture were $4.21 \mathrm{Mpa}, 722.78 \mathrm{Mpa}$, and $1.66 \%$, respectively. The color of the films was influenced by the oil content, with the films with higher buriti oil concentrations characterized as having a yellowish, dark, intense color. The incorporation of buriti oil in the films increased their content of flavonoids, tannins, and carotenoids, which are known to have beneficial effects on human health. Furthermore, the films supplemented with buriti oil showed antioxidant activity, with potential applications as active and bioactive packaging materials for food. The chosen composition of the factorial design was the central formulation, containing $0.3 \%$ of buriti oil and $0.03 \%$ of emulsifier, with properties suitable for applications as packaging for foods.

Author Contributions: Conceptualization, D.S.d.C., K.P.T., J.G.d.O.F., M.R.V.B., M.B.E. and G.R.P.; methodology, D.S.d.C., K.P.T. and R.M.d.S.; formal analysis, D.S.d.C. and R.M.d.S.; investigation, D.S.d.C., K.P.T., C.M.B. and R.M.d.S.; writing—original draft preparation, D.S.d.C., K.P.T., J.G.d.O.F. and M.R.V.B.; writing-review and editing, J.G.d.O.F., M.R.V.B., M.B.E. and G.R.P.; supervision, G.R.P.; funding acquisition, G.R.P. All authors have read and agreed to the published version of the manuscript.

Funding: This research received no external funding.

Informed Consent Statement: Not applicable.

Data Availability Statement: Not applicable.

Acknowledgments: The authors acknowledge the financial support of CNPq, IF Goiano, and FAPEG. This study was financed in part by the Coordenação de Aperfeiçoamento de Pessoal de Nível Superior-Brasil (Capes)-Finance Code 001.

Conflicts of Interest: The authors declare no conflict of interest.

\section{References}

1. Oliveira Filho, J.; Bertolo, M.; Rodrigues, M.; Marangon, C.; da Cruz Silva, G.; Odoni, F.; Egea, M. Curcumin: A multifunctional molecule for the development of smart and active biodegradable polymer-based films. Trends Food Sci. Technol. 2021, 118, 840-849. [CrossRef]

2. Henning, F.; Ito, V.C.; Demiate, I.; Lacerda, L. Non-conventional starches for biodegradable films: A review focussing on characterisation and recent applications in food. Carbohydr. Polym. Technol. Appl. 2021, 100157. [CrossRef]

3. Shaikh, S.; Yaqoob, M.; Aggarwal, P. An overview of biodegradable packaging in food industry. Curr. Res. Food Sci. 2021, 4, 503-520. [CrossRef] [PubMed]

4. Cui, C.; Ji, N.; Wang, Y.; Xiong, L.; Sun, Q. Bioactive and intelligent starch-based films: A review. Trends Food Sci. Technol. 2021, 116, 854-869. [CrossRef]

5. de Oliveira Filho, J.G.; Albiero, B.R.; Cipriano, L.; Bezerra, C.C.d.O.N.; Oldoni, F.C.A.; Egea, M.B.; de Azeredo, H.M.C.; Ferreira, M.D. Arrowroot starch-based films incorporated with a carnauba wax nanoemulsion, cellulose nanocrystals, and essential oils: A new functional material for food packaging applications. Cellulose 2021, 28, 6499-6511. [CrossRef]

6. Zhang, Y.; Simpson, B.; Dumont, M.-J. Effect of beeswax and carnauba wax addition on properties of gelatin films: A comparative study. Food Biosci. 2018, 26, 88-95. [CrossRef] 
7. Cooper, T. Developments in plastic materials and recycling systems for packaging food, beverages and other fast-moving consumer goods. In Trends in Packaging of Food, Beverages and Other Fast-Moving Consumer Goods (FMCG); Farmer, N., Ed.; Woodhead Publishing: Sawston, UK, 2013; pp. 58-107.

8. Seydim, A.; Sarikus, G. Antimicrobial activity of whey protein based edible films incorporated with oregano, rosemary and garlic essential oils. Food Res. Int. 2006, 39, 639-644. [CrossRef]

9. Song, N.-B.; Lee, J.-H.; Al Mijan, M.; Song, K. Development of a chicken feather protein film containing clove oil and its application in smoked salmon packaging. LWT-Food Sci. Technol. 2014, 57, 453-460. [CrossRef]

10. Leão, K.M.M.; Reis, L.V.C.; Speranza, P.; Rodrigues, A.P.; Ribeiro, A.P.B.; Macedo, J.A.; Macedo, G.A. Physicochemical characterization and antimicrobial activity in novel systems containing buriti oil and structured lipids nanoemulsions. Biotechnol. Rep. 2019, 24, e00365. [CrossRef]

11. Speranza, P.; Ribeiro, A.; Cunha, R.; Macedo, J.; Macedo, G. Influence of emulsion droplet size on antimicrobial activity of interesterified Amazonian oils. LWT-Food Sci. Technol. 2015, 60, 207-212. [CrossRef]

12. de Oliveira Filho, J.G.; Braga, A.R.C.; de Oliveira, B.R.; Gomes, F.P.; Moreira, V.L.; Pereira, V.A.C.; Egea, M.B. The potential of anthocyanins in smart, active, and bioactive eco-friendly polymer-based films: A review. Food Res. Int. 2021, 142, 110202. [CrossRef]

13. Silva, M.d.F.; Lopes, P.S.; da Silva, C.F.; Yoshida, C.M. Active packaging material based on buriti oil-Mauritia flexuosa L.f. (Arecaceae) incorporated into chitosan films. J. Appl. Polym. Sci. 2016, 133, 43210.

14. Silva, N.D.S.E.; Hernández, E.J.G.P.; Araújo, C.D.S.; Joele, M.R.S.P.; Lourenço, L.d.F.H. Development and optimization of biodegradable fish gelatin composite film added with buriti oil. CyTA-J. Food 2018, 16, 340-349. [CrossRef]

15. Almeida, C.B.d.; Corradini, E.; Forato, L.A.; Fujihara, R.; Lopes, J.F. Microstructure and thermal and functional properties of biodegradable films produced using zein. Polímeros 2018, 28, 30-37. [CrossRef]

16. Acosta, S.; Chiralt, A.; Santamarina, P.; Rosello, J.; González-Martínez, C.; Cháfer, M. Antifungal films based on starch-gelatin blend, containing essential oils. Food Hydrocoll. 2016, 61, 233-240. [CrossRef]

17. de Oliveira Filho, J.G.; Bezerra, C.C.d.O.N.; Albiero, B.R.; Oldoni, F.C.A.; Miranda, M.; Egea, M.B.; de Azeredo, H.M.C.; Ferreira, M.D. New approach in the development of edible films: The use of carnauba wax micro- or nanoemulsions in arrowroot starch-based films. Food Packag. Shelf Life 2020, 26, 100589. [CrossRef]

18. Ramos, O.; Silva, S.; Soares, J.; Fernandes, J.; Poças, M.; Pintado, M.; Malcata, F. Features and performance of edible films, obtained from whey protein isolate formulated with antimicrobial compounds. Food Res. Int. 2012, 45, 351-361. [CrossRef]

19. E96/E96M-16; Standard Test Methods for Water Vapor Transmission of Materials West Conshohocken. ASTM International: West Conshohocken, PA, USA, 2016.

20. Gontard, N.; Guilbert, S.; Cuq, J.L. Edible wheat gluten films: Influence of the main process variables on film properties using response surface methodology. J. Food Sci. 1992, 57, 190-195. [CrossRef]

21. Tang, C.-H.; Jiang, Y.; Wen, Q.-B.; Yang, X.-Q. Effect of transglutaminase treatment on the properties of cast films of soy protein isolates. J. Biotechnol. 2005, 120, 296-307. [CrossRef]

22. D882-12; Standard Test Method for Tensile Properties of Thin Plastic Sheeting. ASTM International: West Conshohocken, PA, USA, 2012

23. Dewanto, V.; Wu, X.; Adom, K.; Liu, R. Thermal processing enhances the nutritional value of tomatoes by increasing total antioxidant activity. J. Agric. Food Chem. 2002, 50, 3010-3014. [CrossRef]

24. Pelozo, M.I.d.G.; Cardoso, M.L.C.; de Mello, J.C.P. Spectrophotometric determination of tannins and caffeine in preparations from Paullinia cupana var. sorbilis. Braz. Arch. Biol. Technol. 2008, 51, 447-451. [CrossRef]

25. Rodriguez-Amaya, D.; Raymundo, L.; Lee, T.; Simpson, K.; Chichester, C. Carotenoid pigment changes in ripening Momordica charantia fruits. Ann. Bot. 1976, 40, 615-624. [CrossRef]

26. Mensor, L.; Menezes, F.; Leitão, G.; Reis, A.; Santos, T.d.; Coube, C.; Leitão, S. Screening of Brazilian plant extracts for antioxidant activity by the use of DPPH free radical method. Phytother. Res. 2001, 15, 127-130. [CrossRef]

27. Oliveira Filho, J.; Rodrigues, J.; Valadares, A.; Almeida, A.; Lima, T.; Takeuchi, K.; Alves, C.; Sousa, H.; Silva, E.; Dyszy, F.; et al. Active food packaging: Alginate films with cottonseed protein hydrolysates. Food Hydrocoll. 2019, 92, 267-275. [CrossRef]

28. Qin, Y.; Liu, Y.; Zhang, X.; Liu, J. Development of active and intelligent packaging by incorporating betalains from red pitaya (Hylocereus polyrhizus) peel into starch/polyvinyl alcohol films. Food Hydrocoll. 2020, 100, 105410. [CrossRef]

29. Zamudio-Flores, P.; Ochoa-Reyes, E.; Ornelas-Paz, J.d.J.; Tirado-Gallegos, J.; Bello-Pérez, L.; Rubio-Ríos, A.; Cárdenas-Felix, R. Caracterización fisicoquímica, mecánica y estructural de películas de almidones oxidados de avena y plátano adicionadas con betalaínas. Agrociencia 2015, 49, 483-498.

30. Ortega-Toro, R.; Jiménez, A.; Talens, P.; Chiralt, A. Effect of the incorporation of surfactants on the physical properties of corn starch films. Food Hydrocoll. 2014, 38, 66-75. [CrossRef]

31. Mendes, J.; Norcino, L.; Martins, H.; Manrich, A.; Otoni, C.; Carvalho, E.; Piccoli, R.; Oliveira, J.; Pinheiro, A.; Mattoso, L. Correlating emulsion characteristics with the properties of active starch films loaded with lemongrass essential oil. Food Hydrocoll. 2020, 100, 105428. [CrossRef]

32. Wang, B.; Sui, J.; Yu, B.; Yuan, C.; Guo, L.; Abd El-Aty, A.; Cui, B. Physicochemical properties and antibacterial activity of corn starch-based films incorporated with Zanthoxylum bungeanum essential oil. Carbohydr. Polym. 2021, 254, 117314. [CrossRef] 
33. Atarés, L.; Chiralt, A. Essential oils as additives in biodegradable films and coatings for active food packaging. Trends Food Sci. Technol. 2016, 48, 51-62. [CrossRef]

34. Kosobutskii, V. Pyrocatechol and its derivatives as antioxidants and prooxidants. Russ. J. Gen. Chem. 2014, 84, 839-842. [CrossRef]

35. Funakoshi-Tago, M.; Nonaka, Y.; Tago, K.; Takeda, M.; Ishihara, Y.; Sakai, A.; Matsutaka, M.; Kobata, K.; Tamura, H. Pyrocatechol, a component of coffee, suppresses LPS-induced inflammatory responses by inhibiting NF- $\mathrm{kB}$ and activating Nrf2. Sci. Rep. 2020, $10,1-17$.

36. Anisah, L.; Syafii, W.; Pari, G.; Sari, R. Antidiabetic activities and identification of chemical compound from samama (Anthocephalus macrophyllus (Roxb) Havil). Indones. J. Chem. 2018, 18, 66-74. [CrossRef]

37. Wang, T.-Y.; Li, Q.; Bi, K.-S. Bioactive flavonoids in medicinal plants: Structure, activity and biological fate. Asian J. Pharm. Sci. 2018, 13, 12-23. [CrossRef] [PubMed]

38. Liu, J.-C.; Hsu, F.-L.; Tsai, J.-C.; Chan, P.; Liu, J.-H.; Thomas, G.; Tomlinson, B.; Lo, M.-Y.; Lin, J.-Y. Antihypertensive effects of tannins isolated from traditional Chinese herbs as non-specific inhibitors of angiontensin converting enzyme. Life Sci. 2003, 73, 1543-1555. [CrossRef]

39. Yugarani, T.; Tan, B.; Teh, M.; Das, N. Effects of polyphenolic natural products on the lipid profiles of rats fed high fat diets. Lipids 1992, 27, 181-186. [CrossRef]

40. Serrano, J.; Puupponen-Pimiä, R.; Dauer, A.; Aura, A.M.; Saura-Calixto, F. Tannins: Current knowledge of food sources, intake, bioavailability and biological effects. Mol. Nutr. Food Res. 2009, 53, S310-S329. [CrossRef]

41. Santos, M.; Alves, R.; Roca, M. Carotenoid composition in oils obtained from palm fruits from the Brazilian Amazon. Grasas $Y$ Aceites 2015, 66, e086.

42. Albuquerque, M.; Guedes, I.; Alcantara Jr, P.; Moreira, S.; Barbosa Neto, N.; Correa, D.; Zilio, S. Characterization of Buriti (Mauritia flexuosa L.) oil by absorption and emission spectroscopies. J. Braz. Chem. Soc. 2005, 16, 1113-1117. [CrossRef]

43. Rao, A.; Rao, L. Carotenoids and human health. Pharmacol. Res. 2007, 55, 207-216. [CrossRef]

44. Saini, R.; Nile, S.; Park, S. Carotenoids from fruits and vegetables: Chemistry, analysis, occurrence, bioavailability and biological activities. Food Res. Int. 2015, 76, 735-750. [CrossRef] [PubMed]

45. Milani, A.; Basirnejad, M.; Shahbazi, S.; Bolhassani, A. Carotenoids: Biochemistry, pharmacology and treatment. Br. J. Pharmacol. 2017, 174, 1290-1324. [CrossRef] [PubMed]

46. Speranza, P.; de Oliveira Falcao, A.; Macedo, J.A.; Da Silva, L.; Rodrigues, A.D.C.; Macedo, G.A. Amazonian Buriti oil: Chemical characterization and antioxidant potential. Grasas Aceites 2016, 67, e135. [CrossRef]

47. Oliveira Filho, J.; Lemes, A.; Braga, A.; Egea, M. Biodegradable Eco-Friendly Packaging and Coatings Incorporated of Natural Active Compounds. In Food Packaging: Advanced Materials, Technologies, and Innovations; Rangappa, S.M., Parameswaranpillai, J., Thiagamani, S.M.K., Krishnasamy, S., Siengchin, S., Eds.; CRC Press: Boca Raton, FL, USA, 2020; pp. 171-205.

48. Silverstein, R.; Webster, F.; Kiemle, D. Identificação Espectrométrica de Compostos Orgânicos, 7th ed.; LTC: Rio de Janeiro, Brazil, 2007; p. 490. 